\title{
A 340 year record of biogenic sulphur from the Weddell Sea area, Antarctica
}

\author{
E. C. Pasteur, R. Mulvaney, D. A. Peel, \\ British Antarctic Survey, High Cross, Madingley Road, Cambridge CB3 OET, England
}

E. S. Saltzman and P-Y Whung

Rosenstiel School of Marine and Atmospheric Science, Division of Marine and Atmospheric Chemistry, 4600 Rickenbacker Causeway,

Miami, FL 33149, U.S.A.

\begin{abstract}
Detailed records of methanesulphonic acid (MSA) and non-sea-salt sulphate (nss $\mathrm{SO}_{4}{ }^{2}$ ) have been obtained from ice cores drilled on Dolleman Island on the east coast of the Antarctic Peninsula $\left(70^{\circ} 35.2^{\prime} \mathrm{S}, 60^{\circ} 55.5^{\prime} \mathrm{W}\right)$. Annual average concentrations of MSA are presented for the period 1652-1992. Over this time span. the mean annual concentration of MSA is $0.69 \mu \mathrm{eq}{ }^{1}(\sigma=0.33, n=340)$, the range is $0.13-2.35 \mu \mathrm{eq} 1^{1}$, and the MSA/nss-SO ${ }_{4}^{2-}$ ratio is 0.22 . The high MSA concentration reflects the proximity of the Weddell Sea, believed to be a region of high marine phytoplankton production. The overall mean nss- $-\mathrm{SO}_{4}{ }^{2}$ concentration is about $66 \%$ of the total sulphate deposited in the snowfall. Low-frequency variations of MSA and oxygen-isotope signals correlate closely, indicating that they mav be modulated by similar atmospheric processes. Positive correlations are observed between the oxygenisotope signature and both MSA $(r=0.41)$ and nss $\mathrm{SO}_{4}{ }^{2-}(r=0.50)$, significant at the $99 \%$ level. A small negative correlation can be seen between both species and the annual duration of sea ice at Scotia Bay, Laurie Island in the South Orkneys, since 1902 (MSA $r=0.23$, and nss $\mathrm{SO}_{4}{ }^{2-} r=-0.29$; significant at $95 \%$ confidence). No significant link between high MSA concentrations and El Niño events is observed at this location.
\end{abstract}

\section{INTRODUCTION}

Methanesulphonic acid (MSA) is produced by the oxidation of dimethyl sulphide (DMS) in the remote marine atmosphere, in a branching mechanism which also produces sulphate (Saltzman, 1983; Bates and others, 1987). This mechanism is the only known source of MSA in ice cores, while sulphate also comes from sea salt and in small concentrations from volcanic activity and anthropogenic sources. DMS is derived from the metabolism of marine phytoplankton in the ocean and is now recognised as an important source of sulphur to the global sulphur budget and in the cycling of sulphur in the atmosphere. Charlson and others (1987) proposed that DMS might be involved in climate forcing, via its role in the production of cloud condensation nuclei $(\mathrm{CCN})$. An increase in the flux of DMS may cause a rise in the CCN population (Bates and others, 1987), resulting in an increase in cloud albedo over the ocean, thus lowering the incident solar radiation. As no longterm record of DMS concentrations exists, the study of MSA and sulphate concentrations in ice cores may prove fundamental in providing information about past trends in DMS concentration and, by implication, past marine biogenic activity. MSA has been measured through the
Last Glacial Period and previous interglacial periods in an ice core from Antarctica (Legrand and others, 1991). MSA concentrations were found to be higher during colder glacial periods than the Interglacial and Holocene, suggesting that MSA production is related to temperature. In Greenland, however, studies by Hansson and Saltzman (1993) in the Renland ice core showed lower MSA concentrations during the Last Glacial Period.

The ratio of $\mathrm{MSA} / \mathrm{nss} \mathrm{SO}_{4}{ }^{2-}$ may be a guide to the origin of sulphur species in the atmosphere, as it appears to be dependent on latitude (Bates and others, 1992. Higher ratios have been measured in the Antarctic Ocean atmosphere compared to the warmer remote Pacific (see Table 1). In ice cores, $\mathrm{MSA} / \mathrm{nss}-\mathrm{SO}_{4}{ }^{2-}$ ratios appear to be lower at higher-altitude sites indicating that long-range transport from a low-latitude source dominates local snowfall (Legrand and others, 1992). The greater DMS emissions and higher MSA/nss- $\mathrm{SO}_{4}{ }^{2}$ ratios observed at high latitudes are likely to be dependent on both temperature and the presence of sea ice. Marine phytoplankton growth occurs under sea ice and in pockets or channels in the ice. Phytoplankton are particularly abundant in the ice-edge zone, where the sea ice is thin enough to allow sufficient light penetration 
Table 1. Mean MSA and nss-SO ${ }_{4}^{2-}$ concentrations and ratios in aerosol samples and ice cores

\begin{tabular}{|c|c|c|c|c|c|c|c|c|}
\hline Location & Source & Latitude & Longitude & $\begin{array}{c}\text { Allitude } \\
\text { m }\end{array}$ & $\begin{array}{c}\text { Mean } \\
M S A \\
\mathrm{ng} \mathrm{m}^{-3}\end{array}$ & $\begin{array}{c}\text { Mean } \\
\text { nss } \mathrm{SO}_{+}^{2} \\
\mathrm{ng} \mathrm{m}^{-3}\end{array}$ & Ratio & Reference \\
\hline
\end{tabular}

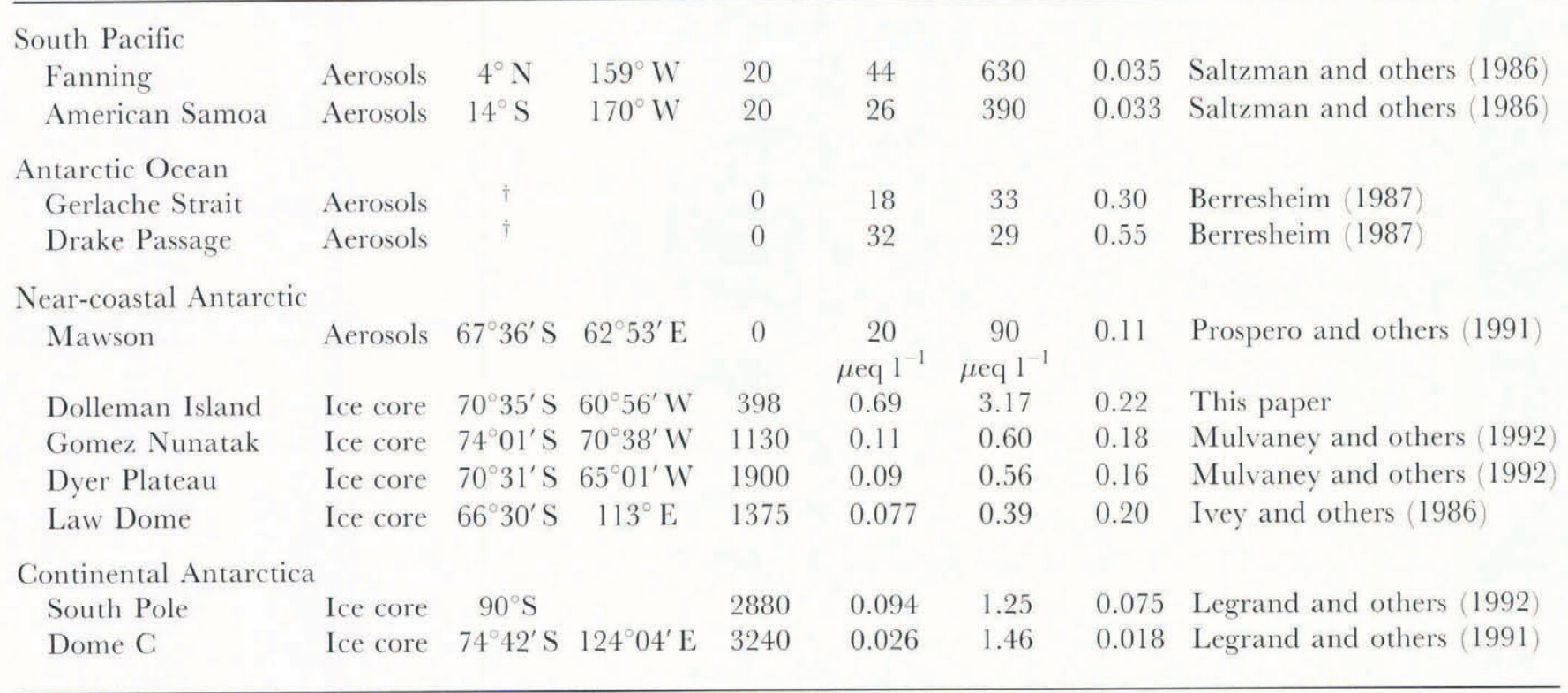

\footnotetext{
* Sulphur equivalent ratio (to obtain molar ratio multiply figure by 2 ).

$\dagger$ Mean of several measurements across the area.
}

for growth (Sakshaug and Skjoldal, 1989). Elevated concentrations of DMS have been recorded in regions where there is floating ice (Berresheim, 1987; Gibson and others, 1989). Welch and others (1993) found a positive relationship between MSA and sea-ice extent at a coastal location adjacent to the Ross Sea.

Data from a South Pole firn core have suggested a link between the El Niño Southern Oscillation (ENSO) phenomenon and MSA concentrations. El Niño is a semi-periodic phenomenon which occurs every $2-10$ years and is linked to elevated sea-surface temperatures, increased rainfall and weak trade winds over the tropical Pacific Ocean. It is associated with a pressure anomaly between the southeast Pacific high-pressure zone and the north-Australian-Indonesian low-pressure zone (Philander, 1983). This affects the global atmospheric circulation and can have long-range effects. Legrand and FenietSaigne (1991) found that during the previous 60 years many of the higher MSA peaks had coincided with reported El Niño events.

Previous studies of MSA and sulphate have been made on ice cores from the interior of the Antarctic, where the source is at a great distance and transport mechanisms play a large role in the modulation of the signal. In this study, we investigate the record of MSA and sulphate in an ice core taken from Dolleman Island. Snow deposited here has usually travelled across sea ice, and therefore a high proportion of the chemical signal is derived from ocean-atmosphere exchange in the marginal sea-ice zone. We investigate this site, close to the source of high DMS production, in the hope that changes in production rate in response to temperature, sea ice and El Niño can be clearly seen.

\section{EXPERIMENTAL PROGEDURES}

A $133 \mathrm{~m}$ long ice core was drilled on Dolleman Island $\left(70^{\circ} 35.2^{\prime} \mathrm{S}, 60^{\circ} 55.5^{\prime} \mathrm{W}\right)$ in January 1986. Figure 1 shows the location of the drilling site, which was $398 \mathrm{~m}$ a.s.l. and had a $10 \mathrm{~m}$ temperature of $-16.8^{\circ} \mathrm{C}$. A second, $30 \mathrm{~m}$, core was drilled in February 1993, about $1 \mathrm{~km}$ from the original drill site. The $10 \mathrm{~m}$ temperature was again recorded as $-16.8^{\circ} \mathrm{C}$. The mean annual accumulation at this site is $0.34 \mathrm{~m} \mathrm{a}^{-1}$ w.e.

The $133 \mathrm{~m}$ core was collected by electromechanical drill, and the shorter core was drilled using a PICO handdrill. Great care was taken to preserve the pristine condition of the ice cores, and polythene gloves were worn when handling them. The ice cores were stored in the field in snow pits, transported to the U.K. in a deep-freeze container $\left(-20^{\circ} \mathrm{C}\right)$ and subsequently stored at this temperature until sub-sampling and analysis.

The ice cores were sub-sampled using a band-saw to produce about 12 samples per year. The saw blade was initially cleaned by cutting an artificial "core" of ice made from $18 \mathrm{M} \Omega$ ultra-pure water. The outside edges of each section of core were removed to exclude any possible contamination from the drilling process. Samples were melted in polypropylene tubs and then stored in polythene sample bottles. All containers had been rigorously washed several times in $18 \mathrm{M} \Omega$ ultra-pure water, prior to use.

Analyses were carried out for oxygen isotopes and anion $\left(\mathrm{Cl}^{-}, \mathrm{NO}_{3}{ }^{-}, \mathrm{SO}_{4}{ }^{2}\right)$ and cation $\left(\mathrm{Na}^{+}, \mathrm{K}^{+}, \mathrm{Ca}^{2+}\right.$, $\mathrm{Mg}^{2+}$ ) species on the individual samples prior to this study (Mulvaney and Peel, 1988). From these data the annual horizons in the cores were determined, and the 


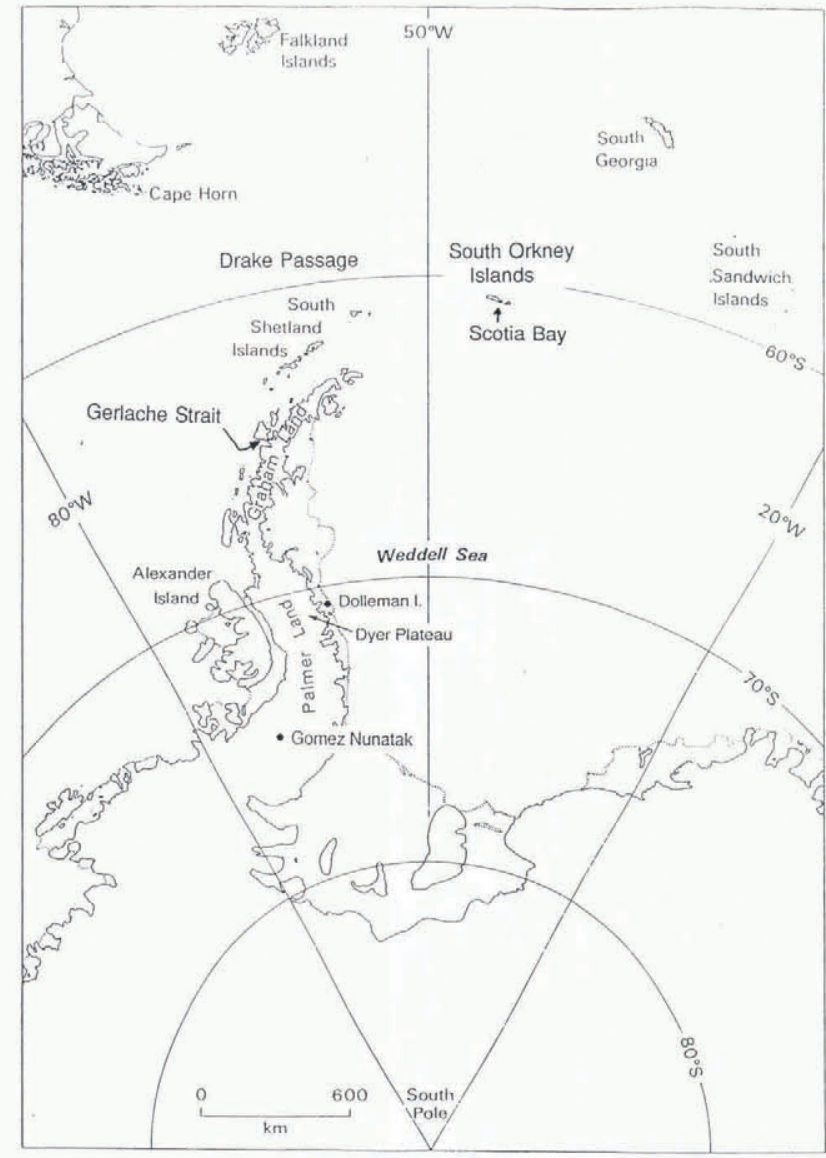

Fig. 1. Map of the Antarctic Peninsula region and the Weddell Sea showing the location of Dolleman Island and Scotia Bay.

samples were then combined to produce one sample per year. Annual composites were made up from between 5 and 21 samples by pipetting equal aliquots of each sample into a new container. The data sequences for the long, $133 \mathrm{~m}$, and the short, $30 \mathrm{~m}$, core were connected by dating the cores and matching the isotope and ionic profiles of the overlapping sections between 1982 and 1949. The $133 \mathrm{~m}$ core was dated from 1982 to 1652 and the short, hand-drilled core from 1992 to 1949. The MSA and nss- $\mathrm{SO}_{4}{ }^{2}$ data from the shorter core were used for the years 1992-83 in the data reported here, while the earlier data are from the long core.

Analyses for MSA were conducted at the University of
Miami, U.S.A. (1795-1982), and at the British Antarctic Survey, Cambridge, England BAS; 16521794 and 195392). At the University of Miami, MSA analyses were carried out using Dionex AG4/AS4 columns, sodium hydroxide eluents and a preconcentrator column. The detection limit for MSA was $0.1 \mu \mathrm{g} \mathrm{kg}^{-1}\left(0.001 \mu \mathrm{eq} \mathrm{l}^{1}\right)$. At the BAS, MSA, chloride and sulphate analyses were carried out on a Dionex 2010 ion chromatograph using AG11/AS11 columns, a hydroxide eluent and a gradient pump. Samples were injected via a $200 \mu 1$ sample loop. Sulphate and chloride were also measured using AG4A AS4A columns, a carbonate eluent and a concentrator column to achieve a sample size of $2 \mathrm{ml}$. The detection limit for all ions was about $0.1 \mu \mathrm{g} \mathrm{kg}{ }^{\prime}$. Analyses at the BAS were carried out in a class-100 clean laboratory. Blanks were also analyzed; MSA was undetectable, whilst other anions were around the detection limit for each species.

Discrete samples from the long, $133 \mathrm{~m}$, core were measured for MSA at the BAS for the period 1953 83, and the averaged mean annual data were compared to the results from Miami. Also, the overlapping sections of the short, $30 \mathrm{~m}$, core and the long, $133 \mathrm{~m}$, core were dated and compared. Finally, a sequence of 14 individual samples in the range 0.01-1.25 $\mu \mathrm{eql} \mathrm{l}^{-1}$ MSA were analyzed at both the University of Miami and the BAS. The results from all of these comparisons are shown in Table 2.

\section{RESULTS}

The MSA record for the period 1652-1992 is shown in Figure 2b. The data have been smoothed binomially over 5 years to minimise the influence of any errors in dating and to allow for the possible relocation of MSA into the adjacent winter snow layer in the ice core Mulvaney and others, 1992). The annual average MSA concentrations vary from 0.13 to $2.35 \mu \mathrm{eq} \mathrm{I}^{-1}$, with a mean value of $0.69 \mu \mathrm{eq} \mathrm{I}^{-1}$. This is unusually high compared to elsewhere in Antarctica (see Table 1), a consequence of the proximity of the biologically productive Weddell Sea. Low-frequency variations are shown by plotting a seventh-order polynomial through the data. This indicates higher concentrations of MSA during the early part of the 18th century, the middle of the 19th century and the latter part of the 20th century, and it appears that there is a cyclical pattern in the data. The mean concentration of MSA for the 19th century $\left(0.78 \mu \mathrm{eq} \mathrm{I}^{-1}\right.$;

Table 2. Comparison of MSA dala analyzed in Miami and at the BAS and of overlapping sections of two cores

\begin{tabular}{|c|c|c|c|c|c|c|}
\hline Samples for comparison & $\begin{array}{c}\text { Measured } \\
\text { al }\end{array}$ & Samples for comparison & $\begin{array}{c}\text { Measured } \\
\text { at }\end{array}$ & $\begin{array}{l}\text { Number of } \\
\text { data points }\end{array}$ & $\begin{array}{l}\text { t-test } \\
\text { value }\end{array}$ & $\begin{array}{c}\text { Confidence limit } \\
\%\end{array}$ \\
\hline $\begin{array}{l}\text { Composite samples } \\
\text { for } 133 \mathrm{~m} \text { core }\end{array}$ & Miami & $\begin{array}{l}\text { Composite samples for } \\
133 \mathrm{~m} \text { core }\end{array}$ & BAS & 14 & 28.2 & 99 \\
\hline $\begin{array}{l}\text { Composite samples } \\
\text { for } 133 \mathrm{~m} \text { core }\end{array}$ & Miami & $\begin{array}{l}\text { Raw data, averaged } \\
\text { for } 133 \mathrm{~m} \text { core }\end{array}$ & BAS & 30 & 2.39 & 95 \\
\hline $\begin{array}{l}\text { Composite samples } \\
\text { for } 133 \mathrm{~m} \text { core }\end{array}$ & Miami & $\begin{array}{c}\text { Raw data, averaged for } \\
30 \mathrm{~m} \text { core - overlap }\end{array}$ & BAS & 32 & 1.92 & 90 \\
\hline
\end{tabular}




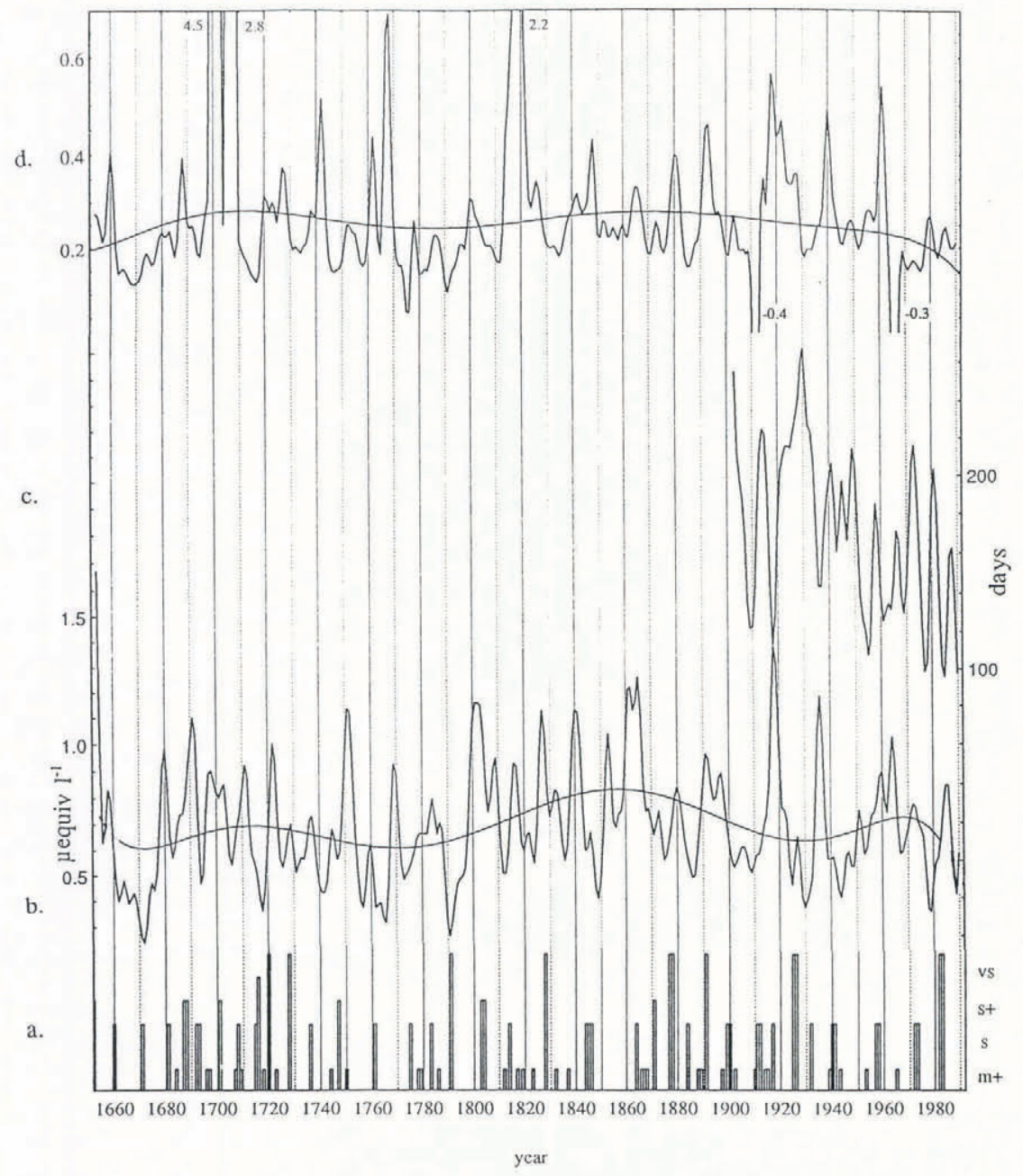

Fig. 2. Comparison of a. Reported El Niño events; b. Annual composite MSA concentration at Dolleman Island; $c$. Duration of sea ice al Scotia Bay, Laurie Island; d. MSA/nss $\mathrm{SO}_{4}{ }^{2}$ at Dolleman Island.

s.d. $=0.20$ is higher than for the 18 th and 20 th centuries $\left(0.62\right.$ and $0.67 \mu \mathrm{eq} \mathrm{l}^{-1}$; s.d. $=0.18$ and 0.20 , respectively $)$.

El Niño Southern Oscillation (ENSO) events, compiled by Quinn and others (1987) are shown in Figure 2a. The events have been characterized as very strong (VS), strong $(\mathrm{S})$ or moderate $(\mathbf{M})$. We have investigated the phase-matching of the stronger EI Niño events with high MSA peaks in the Dolleman Island record. Ten peaks in the smoothed MSA data have concentrations of greater than $1 \mu \mathrm{eq} l^{-1}$. Five of these were within 1-2 years of an El Niño event characterized as having a strength of $\mathrm{M}+$ or greater, and of these only one was a VS event. Out of the eight reported VS events, four coincided with local maxima in the MSA data, and one coincided with one of the lowest minima in the record. This is not a strong argument for a direct relationship between MSA and El Niño events at this location. No better match was found when the profiles were compared with lags of up to 2 years. The effect of El Niño events on marine biogenic activity and on atmospheric circulation in the Antarctic is still poorly understood. At the South Pole, Legrand and Feniet-Saigne (1992) reported a phase correlation between El Niño and MSA concentrations over the past 60 years. The difference between the records from Dolleman Island and those from the South Pole may result from the difference in source region and atmo- spheric circulation. At the South Pole, there are typically only a few snowfall events in a year, and accumulation rates are low. Also, this site has a very large and distant source region, and incoming air masses are typically very well mixed. Dolleman Island experiences year-round snowfall from a more local source, with high accumulation rates giving a well-balanced year-round signal of chemical species in the ice core.

Welch and others (1993) found a correlation between MSA and sea-ice extent at their sampling site at Newall Glacier $\left(77^{\circ} 35^{\prime} \mathrm{S}, 162^{\circ} 30^{\prime} \mathrm{E}\right)$, close to the Ross Sea. When more sea ice was present, a greater concentration of MSA was measured. Within sea ice, breaks, leads and polynyas can form, giving open water (Carsey, 1980; Chiu, 1983; Comiso and Gordon, 1987). These provide an ideal growing habitat for marine phytoplankton, as both light ice and thin, broken ice are available. Consequently, the overall extent of sea ice may be less important than the density of the ice.

We have compared our MSA data with the annual sea-ice duration (Fig. 2c) recorded at Scotia Bay, Laurie Island in the South Orkney Islands (Heap, 1962; Mayes 1981; personal communication from C. Symon, 1992). Scotia Bay lies near the northern edge of the mean maximum extent of ice cover and is therefore sensitive to changes in ice cover in this region. The data are presented 
as the number of days per year on which sea ice was present in the bay. The sea-ice duration data have a small but significant anti-correlation with $\mathrm{MSA}$ and nss- $\mathrm{SO}_{4}{ }^{2}$ concentrations and oxygen-isotope ratios (MSA $r=-0.23 ;$ nss $\mathrm{SO}_{4}{ }^{2} r=-0.29 ; \delta^{18} \mathrm{O} r=-0.21, n=88$; all significant at $95 \%$ confidence). The anti-correlation is in fact quite strong until about 1955. The Weddell Sea is affected by a westerly circulation of the ocean current called the Weddell Gyre. This forces the sea ice around in a clockwise direction, pushing ice up along the spine of the peninsula into the northwest corner of the Weddell Sea. Ice cover in Scotia Bay is more likely when the Weddell Gyre is stronger. In the region of Dolleman Island this will result in greater ice cover adjacent to the island and less local open water with lower local production of DMS. A weaker westerly circulation, evident from no sea ice in Scotia Bay, may lead to a greater areal extent of ice in the Weddell Sea and therefore more chance of local open water. This may partly account for the weak anti-correlation of MSA concentration with Scotia Bay sea ice.

The nss- $\mathrm{SO}_{4}{ }^{2-}$ concentration was obtained from total sulphate by subtracting the calculated sea-salt component of the sulphate from the total sulphate. $\mathrm{Cl} / \mathrm{Na}$ was calculated in a section of the Dolleman Island core (1124 samples, $\mathrm{Cl} / \mathrm{Na}=1.38$ ) and is very close to the bulk sea-water ratio Charlson and Schwartz, 1992; Peel, in press). Chloride concentrations were therefore used to calculate the nss- $\mathrm{SO}_{4}{ }^{2-}$ component in each sample using the following expression:

$$
\left[\mathrm{SO}_{4}{ }^{2-}\right]_{\mathrm{nss}}=\left[\mathrm{SO}_{4}{ }^{2-}\right]_{\text {total }}-0.103\left[\mathrm{Cl}^{-}\right] \text {in } \mu \mathrm{eql} \mathrm{l}^{-1}
$$

The nss $\mathrm{SO}_{4}{ }^{2}$ makes up $66 \%$ of the total sulphate in this core, indicating that the marine biogenic component is a very important source of sulphur to the sulphur budget. Volcanic and anthropogenic sulphur may also contribute to the nss-SO ${ }_{4}{ }^{2}$ signal, but levels are likely to be minimal compared to the biogenic sulphur input at this lowaltitude site close to a region of high oceanic-sulphur production.

The ratio of MSA/nss $\mathrm{SO}_{4}{ }^{2}$ is shown in Figure 2d. The mean MSA/nss $\mathrm{SO}_{4}{ }^{2}$ is 0.22 (ratio of the two means, $n=341$ ). There are several outliers which occur when there are abnormally high chloride concentrations (which may be associated with high winds, and in these few samples we have rather low nss $\mathrm{SO}_{4}{ }^{2-}$ which, taken with normal MSA concentrations, produces the high ratios. Again a seventh-order polynomial has been plotted through the data to highlight long-term variations in the signal. The trend in MSA/nss $\mathrm{SO}_{4}{ }^{2}$ is more stable than MSA itself over the long term, even though there is much year-to-year variation, implying that the source area of MSA has not changed significantly in the past 340 years.

Figure 3 shows the relationship between MSA and oxygen-isotope ratio. The correlation of the two species is significant at the $99 \%$ confidence limit $r=0.41$, $n=341$ ). In another Antarctic ice core, Legrand and others (1991) found a negative correlation between MSA and temperature derived from isotopes. That study was concerned with the comparison between ice-age and interglacial ice where the source environments are likely

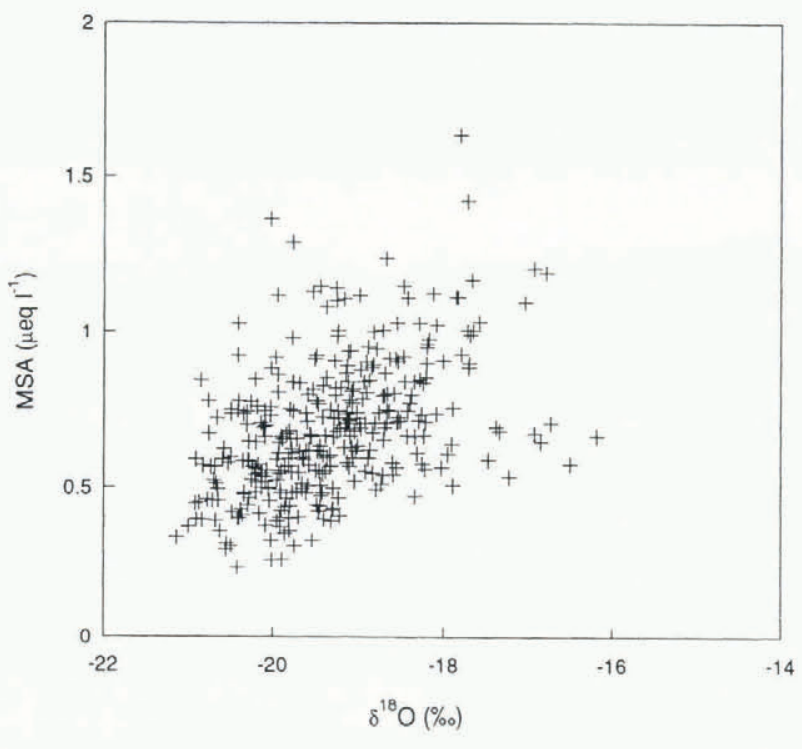

Fig. 3. Scaller plot showing relationship between MSA and oxygen-isotope ratio.

to be radically different. Here, we are looking at a period of relative climatic stability with probably another mechanism governing the relationship between MSA and temperature. In this case it appears that higher MSA concentrations are associated with higher temperatures (derived from isotope data). This may be due to breakup of the sea ice and a greater number of leads within the Weddell Sea during warmer summers.

\section{CONCLUSIONS}

MSA concentrations in ice cores from Dolleman Island are consistently high over the past 340 years, confirming that the Weddell Sea is a region of high DMS production. Over this period, higher concentrations found in the mid19 th century imply increased biological productivity or a change in transport favouring the deposition of MSA. At this location, we found no significant phase relationship between El Nino events and the MSA record such as has been observed at the South Pole. A comparison with seaice extent at Scotia Bay in the South Orkney Islands shows a small negative correlation with MSA concentrations from Dolleman Island. During periods of increased sea ice at Scotia Bay the amount of open water in the west of the Weddell Sea may be reduced, leading to a lower production rate for DMS. The low-frequency variation in $\mathrm{MSA} / \mathrm{nss} \mathrm{SO}_{4}{ }^{2-}$ remains fairly constant over the past 340 years, indicating that there has been no major change in the relative production of the two species and no significant change in the source area. A positive correlation is reported for the relationship between MSA and oxygen-isotope ratio. This implies greater MSA production at warmer temperatures, which may be linked with the amount of broken sea ice available as habitat for DMS-producing phytoplankton.

There is still much to be learnt about the relative processes affecting the production, transfer and reaction of DMS in the atmosphere and in the transport and 


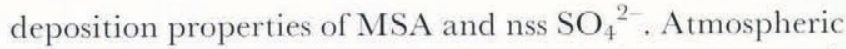
circulation, temperature variations and phenomena such as ENSO will all contribute in different ways to the relative concentrations measured in the ice. By investigating a detailed set of measurements of biogenic sulphur species in the ice in the context of their location, we hope to obtain a better understanding of the mechanisms involved.

\section{REFERENCES}

Bates, T.S., J.A. Calhoun and P.K. Quinn. 1992. Variations in the methanesulfonate to sulfate molar ratio in submicrometer marine aerosol particles over the South Pacific area. 7. Geoplyys. Res., 97 (D9), 9859-9865.

Bates, T. S., R.J. Charlson and R. H. Gammon. 1987. Evidence for the climatic role of marine biogenic sulphur. Nature, $\mathbf{3 2 9} 6137), 319$ 321 .

Berresheim, H. 1987. Biogenic sulfur emissions from the subantarctic and Antarctic oceans. J. Geophys. Res., 92(D11), 13,245-13,262.

Carsey, F.D. 1980. Microwave observation of the Weddell polynya. Mon. Weather Rev., 108, 20322044.

Charlson, R.J. and S.E. Schwartz. 1992. Climate forcing by anthropogenic aerosols. Science, 255, 423-430.

Charlson, R. J., J. E. Lovelock, M. O. Andreae and S. G. Warren. 1987. Oceanic phytoplankton, atmospheric sulphur, cloud albedo and climate. Nature, 326(6114), 655-661.

Chiu, L. S. 1983. Antarctic sea ice variations 1973-1980. In StreetPerrott, A., M. Beran and R. Radcliffe, eds. Variations in the global water budget. Dordrecht, etc., D. Reidel Publishing Co., 301-311.

Comiso, J.C. and A.L. Gordon. 1987. Recurring polynyas over the Cosmonaut Sea and the Maud Rise. F. Geophys. Res., 92 C3), 28192833.

Gibson, J. A.E., R. C. Garrick, H. R. Burton and A. R. MeTaggart. 1989. Dimethylsulphide and the alga Phaeocystis pouchetii in Antarctic coastal waters. Mar. Biol., 104, 339-346.

Hansson, M. E. and E. S. Saltzman. 1993. The first Greenland ice core record of methanesulfonate and sulfate over a full glacial cycle. Geophys. Res. Lett., 20 (12), 1163-1166.

Heap, J. A. 1962. Sea ice distribution in the Antarctic between $7^{\circ} \mathrm{W}$ and $92^{\circ}$ W. (Ph.D. thesis, University of Cambridge.)
Ivey, J.P., D. M. Davies, V. Morgan and G. P. Ayers. 1986. Methanesulphonate in Antarctic ice. Tellus, 38B (5), 375-379.

Legrand, M. and C. Feniet-Saigne. 1991. Methanesulfonic acid in south polar snow layers: a record of strong El Niño? Geophys. Res. Lett., $18(2), 187-190$.

Legrand, M., C. Feniet-Saigne, E. S. Saltzman, C. Germain, N. I. Barkov and V.N. Petrov. 1991. Ice-core record of oceanic emissions of dimethylsulphide during the last climate cycle. Nature, $\mathbf{3 5 0}$ (6314), $144-146$.

Legrand, M., C. Feniet-Saigne, E. S. Saltzman and C. Germain. 1992. Spatial and temporal variations of methanesulfonic acid and non sea salt sulfate in Antarctic ice. J. Atmos. Chem., 14 (1-4), 245-260.

Mayes, P.R. 1981. Atmospheric circulation trends in southern South America and the Antarctic Peninsula area. (Ph.D. thesis, University of East Anglia.)

Mulvaney, R. and D. A. Peel. 1988. Anions and cations in ice cores from Dolleman Island and the Palmer Land plateau, Antarctic Peninsula. Ann. Glaciol., 10, 121-125.

Mulvaney, R., E. C. Pasteur, D.A. Peel, E.S. Saltzman and P.-y. Whung. 1992. The ratio of MSA to non-sea-salt sulphate in Antarctic Peninsula ice cores. Tellus, 44B 4), 295-303.

Peel, D. A. In press. The chemistry and climatic role of biogenic sulphur: group discussion. In Ice Core Studies of Global Biogeochemical Cycles. NATO Advanced Research Workshop, 26-31 March 1993, Annecy, France. Berlin, Springer-Verlag. (NATO ASI Series.)

Philander, S.G.H. 1983. El Niño southern oscillation phenomena. Nature, 302, 295-301.

Prospero, J. M., D. L. Savoie, E. S. Saltzman and R. Larson. 1991, Impact of oceanic sources of biogenic sulphur on sulphate aerosol concentrations at Mawson, Antarctica. Nature, 350 6315), 221-223.

Quinn, W.H., V.T. Neal and S. E. Antunez de Mayolo. 1987. El Niño occurrences over the past four and a half centuries. J. Geophys. Res., 92 C13), 14,449-14,461.

Sakshaug, E. and H. R. Skjoldal. 1989. Life at the ice edge. Ambio, 18 (1), $60-67$.

Saltzman, E.S., D. L. Savoie, R.G. Zika and J. M. Prospero. 1983. Methane sulfonic acid in the marine atmosphere. J. Geophys. Res., 88 C.15), 10,897-10,902.

Saltzman, E.S., D. L. Savoie, J. M. Prospero and R. G. Zika. 1986. Methanesulphonic acid and non-sea-salt sulphate in Pacific air: regional and seasonal variations. f. Atmos. Chem., 4, 227-240.

Welch, K. A., P. A. Mayewski and S. I. Whitlow. 1993. Methanesulfonic acid in coastal Antarctic snow related to sea-ice extent. Geophys. Res. Lell., 20 (6), $443-446$. 